\title{
Fast and Simple Tuning Rules of Synchronous Reference Frame Proportional-Integral Current Controller
}

\author{
AHMED M. DIAB ${ }^{\circledR 1,2}$, (Graduate Student Member, IEEE), SERHIY BOZHKO ${ }^{\circledR}$, (Senior Member, IEEE), \\ FENG GUO ${ }^{\circledR 2}$, (Student Member, IEEE), MOHAMED RASHED ${ }^{\circledR 2}$, (Member, IEEE), \\ GIAMPAOLO BUTICCHI ${ }^{1,2}$, (Senior Member, IEEE), ZHUANG XU ${ }^{\circledR 1}$, (Member, IEEE), \\ SEANG SHEN YEOH ${ }^{\circledR}$, CHRIS GERADA ${ }^{\circledR}$, (Senior Member, IEEE), AND \\ MICHAEL GALEA 1,2 , (Senior Member, IEEE) \\ ${ }^{1}$ Key Laboratory of More Electric Aircraft Technology of Zhejiang Province, University of Nottingham Ningbo China, Ningbo 315100 , China \\ ${ }^{2}$ Power Electronic and Machine Control Group, University of Nottingham, Nottingham NG7 2RD, U.K. \\ Corresponding author: Ahmed M. Diab (skxad1@nottingham.edu.cn)
}

This work was supported by the Natural Science Foundation of China through the project under Grant 51850410515.

\begin{abstract}
Synchronous reference frame proportional-integral (PI) current controller (CC) is considered the most well-established solution for the current regulation in electrical drives. However, the gain selection of the PI CC is still regarded to be poorly reported, particularly in relation to the effect of the inevitable execution time taken by the controller and inverter. Mostly, tuning process of PI CC is done by trial and error or using simple rules based on pole zero cancelation and pole placement methods which ignore time delays through the controller and inverter. Hence, PI CC delivers significantly different performance compared to the expected one during the digital implementation, especially if high bandwidth or low ratio between the switching and operational frequency are required. Therefore, this paper firstly addresses and analyses the common tuning rules of PI CC which ignore the existence of time delays followed by a rigorous analysis for PI CCs' robustness to the influence of computational and modulation delays. Based on this analysis, generic recommendations have been proposed to select the PI CCs' gains as a function of the electrical drive switching frequency considering the delay effect. A set of simple, generic, and fast tuning rules were derived that guarantee fast dynamic performance with reasonable stability margins. Moreover, the effects of model uncertainties on these developed rules have been analyzed and reported. Comprehensive experimental results are provided to prove the key analytical results of this study and to validate the proposed design recommendations.
\end{abstract}

INDEX TERMS Current control, delay effect, synchronous reference frame, AC drive system.

\section{INTRODUCTION}

AC synchronous machines have been widely used in many industrial applications, particularly the automotive applications which require high steady-state and dynamic performance. So, developing a control system for the synchronous machines in such applications has a great interest in the last few decades. Field oriented control (FOC) is considered as the most established strategy in the electric drive systems. It consists of cascaded control loops, typically with an inner loop for current regulation and outer loop for speed control.

The associate editor coordinating the review of this manuscript and approving it for publication was Jin-Liang Wang.
It can be argued that the current control loop has a major effect on the overall system performance [1]. Therefore, many studies that investigate various current control schemes are reported in [2]-[5]. The hysteresis controller, for instance, can achieve instantaneous tracking of the reference. However, the wide variation of the switching frequency during the fundamental period in the hysteresis control may lead to irregular inverter operation [2]. Model Predictive current controllers also provide a very fast dynamic response, but they are very sensitive to the model parameter variations [4]. In general, it can be said that the field of current controller (CC) is dominated by synchronous reference frame (SRF) proportional-integral (PI) CCs. Their success 
is mainly due to the inherent simplicity in their design and implementation [6]-[8]. Besides, the fundamental excitation signal in SRF is transformed into dc quantity which easy to be regulated and to achieve zero steady state error using PI controller. However, transformation of the electrical signals to the SRF creates cross -coupling between the orthogonal current components that is proportional to the fundamental operating frequency. So, the performance of the current controller is degraded during the increase of operating speed. So that, great efforts have been applied to enhance further their performance hence generating various configurations of this CC technique. Some researchers introduce the added feedforward terms to compensate the cross-coupling components and mitigate operating frequency effects [8]. Others propose the complex vector SRF PI CC to provide better cross-coupling compensation [7], [9], [10]. The design of the $\mathrm{CC}$ has also been presented in [11], [12] as a multi-input multi output controller which known by dynamic decoupling CC to improve the cross-coupling compensation. The advanced angle delay has been introduced in [13] to improve the control performance by compensating the delay in the angle due to the rotating d-q frame.

However, despite the widespread usage and development of SRF PI CCs, the gains' selection are mostly based on trial and error or common methods, which set rules for the PI gains in order to achieve a targeted performance, such as pole-placement [14], [15], pole/zero cancelation [10], [12], [16], Ziegler-Nichols and Cohen-Coon methods [17], [18]. These rules are based on assumption of no time delay through the current control loop. This time delay refers to the inevitable execution time taken by controller and inverter [13].

In current control loop, the control action is generated based on the difference between reference and measured current (error signal). The generated control signal is responsible for generating the PWM signals to generate ac voltage applied to the machine such that the machine's currents follow the reference values. Ideally, this process should be instant (i.e., synchronized), but in practice the existence of time delays in controller (discrete-time implementation using DSP) and the inverter prevents this synchronization as illustrated by Fig.1. It shows that the control signal is updated at instant $k$ which corresponds to the measured current at previous instant $k-1$. This phenomenon degrades the system performance, including stable operation regions [13], [19]. For many practical applications time delays can be ignored, however in some cases, for example when high bandwidth response or lower switching to operational frequency are required, the performance of digitally implemented CC can be significantly different compared to the expected one due to ignoring the existing time delays [20]. Moreover, high bandwidth operation with negligible overshoot for current controller is desirable for high dynamic performance. Since there are cases where the delay must be taken into account during the $\mathrm{CC}$ design, these tuning methods need to be thoroughly analyzed and evaluated. Therefore, this paper presents

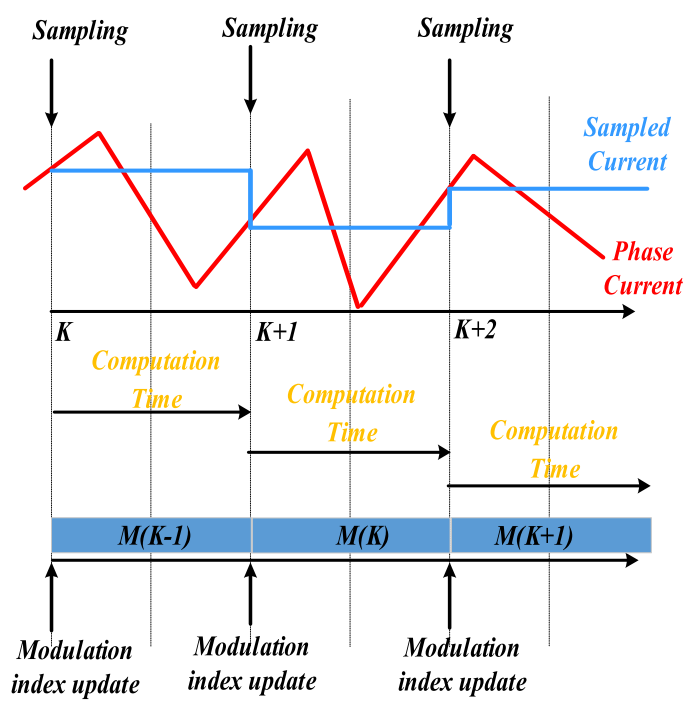

FIGURE 1. Schematic for current measurement sampling compared with the PWM and control signal updates.

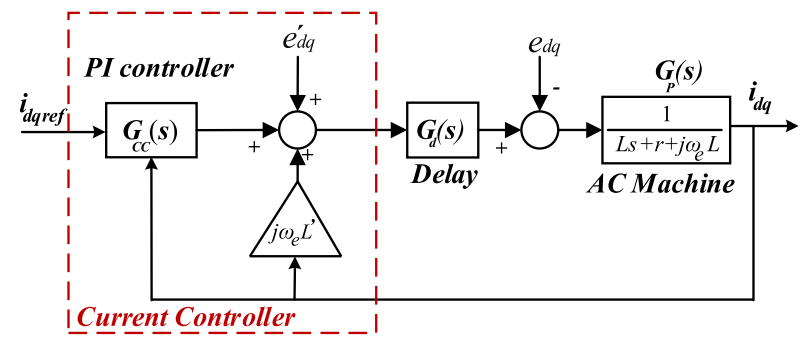

FIGURE 2. Overall block diagram of current control loop in ac machine represented by the complex vector notation.

1- Comprehensive analysis for various possible structures of PI controllers and their common tuning methods which ignore the time delay in their rules.

2- Comparative stability analysis for their robustness to the influence of computational and modulation delays.

3- Proposed simple tuning rules of PI CCs that guarantee fast and robust dynamics with reasonable stability margins considering effects of the time delay.

4- Experimental results to validate the proposed tuning rules and to prove the analytical outcome in this paper.

\section{SRF PI CURRENT CONTROLLER DESIGN SCHEMES}

The general structure of the current control system of AC machine with SRF PI CC overall can be shown in Fig. 2 where the machine model is represented by the complex vector notation in SRF as shown by (1), where $r$ and $L$ are the machine resistance and inductance respectively, and $\omega_{e}$ is the electrical angular velocity [21].

The complex vector notation represents the machine as asymmetric three phases R-L load. The imaginary term in the denominator $j \omega_{e} L$ refers to the cross-coupling terms between orthogonal components of the currents. Their effect can be mitigated by introducing the decoupling current elements 
TABLE 1. Machine parameters.

\begin{tabular}{|l|c|c|}
\hline Parameter & Symbol & Value \\
\hline Phase Resistance & $r$ & $1.058 \mathrm{~m} \Omega$ \\
\hline Phase Inductance & $L_{d}=L_{q}=L$ & $99 \mu \mathrm{H}$ \\
\hline Poles pairs & $p$ & 3 \\
\hline Magnet flux linkage & $\Phi_{m}$ & $0.03644 \mathrm{wb}$ \\
\hline Rated Power & $P_{\text {rated }}$ & $45 \mathrm{kw}$ \\
\hline
\end{tabular}

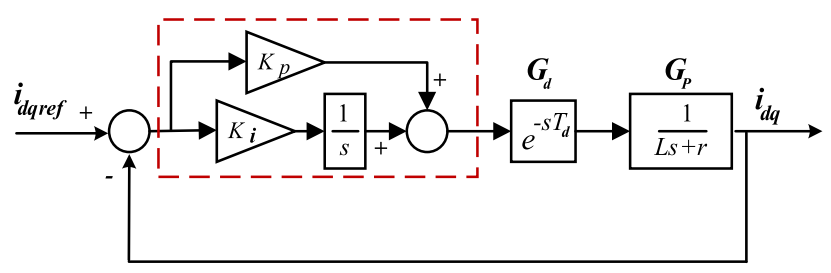

FIGURE 3. Block diagram of the current control loop using the conventional PI CC.

$\left(j \omega_{e} L^{\prime}\right)$ as shown in Fig. 2.

$$
G_{p}(s)=\frac{I_{d q}}{U_{d q}}=\frac{1}{L s+r+j \omega_{e} L}
$$

The execution time delay through the inverter and the controller is shown by the block $G_{d}(s)$ which can be represented in the control system [21] as given in (2), where $T_{d}$ represents the time delay which is typically evaluated in $\mathrm{AC}$ drive systems as 1.5 times of the sampling time $T_{S}$ [9], [22] and considering the one step advanced angle [13]. Note that Ts coincides with the period of the pulse width modulation $(\mathrm{PWM})$ carrier $\left(T_{s w}\right)$ in case of single update mode.

$$
G_{d}(s)=e^{-s T_{d}}
$$

The back EMF of the ac machine $e_{d q}$ and its compensation term $e_{d q}^{\prime}$ are also shown in the block diagram. The difference between them is considered as a disturbance. The PI controller in Fig. 2 can be structured by one or two degree of freedom PI controller which has been discussed in the following subsections. During the CC tuning, operating speed is assumed to be zero as a rule of thumb [23]. Hence, the cross coupling and their compensation elements have been removed during the study of controller's gains selection. The analysis cases in this paper assume controlling the permanent magnet machine with the parameters given in Table 1 .

\section{A. CONVENTIONAL PI CC WITH POLE/ZERO CANCELATION METHOD (1 ${ }^{\text {st }}$ DESIGN)}

The classical PI controller in the current control loop has been considered in this approach as seen in Fig. 3. The open loop transfer function of Fig. 3 can be shown as follows:

$$
G_{o . l}(s)=\frac{K_{p} s+K_{i}}{s} \frac{G_{d}(s)}{L s+r}
$$

The controller gains in (3) are tuned based on the pole zero cancelation method where they are selected according to (4) and (5) [7, 8], where $L^{\prime}$ and $r^{\prime}$ represent the machine nominal parameters in Table 1 . Note that their values might be different from the actual machine parameters $L$ and $r$.

$$
\begin{aligned}
K_{i} & =K_{o} r^{\prime} \\
K_{p} & =K_{o} L^{\prime}
\end{aligned}
$$

If it is assumed that the machine parameters used in the tuning process match the actual values, the corresponding open loop and closed loop transfer functions of Fig. 3 can be expressed by (6) and (7) respectively.

$$
\begin{aligned}
G_{o . l 1 d}(s) & =\frac{K_{o}}{s} G_{d}(s) \\
G_{c . l 1 d}(s) & =\frac{K_{o} G_{d}(s)}{s+K_{o} G_{d}(s)}
\end{aligned}
$$

When the time delay is ignored, the closed loop transfer function can be deduced as given by equation (8) where the current control loop is simplified to a first order system and $K_{o}$ refers to the closed loop system bandwidth.

$$
G_{c . l 1}(s)=\frac{G_{o . l}(s)}{1+G_{o . l}(s)}=\frac{K_{o}}{s+K_{o}}
$$

Consequently, the controller gains can be designed easily based on the targeted bandwidth $K_{o}$.

\section{B. CONVENTIONAL PI CC WITH POLE PLACEMENT METHOD (2 $2^{n}$ DESIGN)}

The classical PI controller shown in Fig. 3 can also be tuned using pole placement method which has been addressed in this section. Based on (3), a general closed loop transfer from Fig. 3 can be expressed by (9).

$$
G_{c . l 2 d}(s)=\frac{\left(K_{i}+K_{p} s\right) G_{d}(s)}{L s^{2}+r s+K_{p} G_{d}(s) s+G_{d}(s) K_{i}}
$$

When the time delay and also the machine parameters errors are ignored, equation (9) can be simplified to a second order system shown by (10).

$$
G_{c . l 2}(s)=\frac{K_{i}+K_{p} s}{L s^{2}+\left(r+K_{p}\right) s+K_{i}}
$$

For pole placement method, the PI gains are set to allocate the closed loop system poles according to desired location to achieve targeted dynamic performance. In these tuning criteria, the PI gains are determined by comparing the denominator of equation (10) and the general form of characteristics polynomial of the second order system $\left(s_{2}+2 \eta \omega_{n} s+\omega_{n}=0\right)$ where $\omega_{n}$ and $\eta$ are the natural frequency and the damping ratio respectively [24]. Finally, the controller gains can be derived as follows:

$$
\left.\begin{array}{l}
K_{p}=\left(2 \eta \omega_{n} L^{\prime}\right)-r^{\prime} \\
K_{i}=\omega_{n}^{2} L^{\prime}
\end{array}\right\}
$$

As shown from (11), the PI gains can be determined based on damping ratio, which is always assumed by 0.707 [23], [25], and natural frequency which can be determined from the targeted bandwidth $(B W)$ as follows [18]:

$$
\omega_{n}=\frac{B W}{\sqrt{1-2 \eta^{2}+\sqrt{4 \eta^{4}-4 \eta^{2}+2}}}
$$




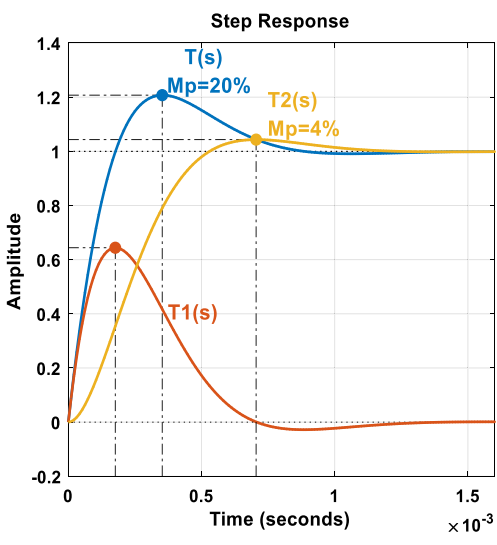

FIGURE 4. Step response of $T_{1}(s), T_{2}(s)$ and $T(s)$.

Despite the simplicity of this method, it has a drawback due to the zero in the closed loop transfer function. This can deprive the controller of obtaining the design requirements in full, even before considering the time delays. Although, this drawback is not related to the delay effect, its impact on the dynamic performance has been analyzed in this section in order to cover the overall change of its dynamic performance during the digital implementation.

This effect can be explained from the analysis of equation (10) as follows:

$$
\begin{aligned}
G_{c . l 2}(s) & =T(s)=\frac{\frac{K_{i}}{L}\left(\frac{K_{p}}{K_{i}} s+1\right)}{s^{2}+\frac{r+K_{p}}{L} s+\frac{K_{i}}{L}} \\
& =\underbrace{\frac{K_{p}}{K_{i}} s T_{d e s}(s)}_{T_{1}(s)}+\underbrace{T_{\text {des }}(s)}_{T_{2}(s)}
\end{aligned}
$$

where

$$
T_{\text {des }}(s)=\frac{\frac{K_{i}}{L}}{s^{2}+\frac{r+K_{p}}{L} s+\frac{K_{i}}{L}}
$$

In (13), it can be observed that the system response has two components, $T_{2}(s)$ which represents the desired response, and $T_{1}(s)$ that refers to the component added by the zero which degrade the performance.

To illustrate the effect of this zero on the loop performance, the step response of $T_{1}(s), T_{2}(s)$ and $T(s)$ are simulated as shown in Fig. 4, using PI gains calculated from (11) to achieve bandwidth $B W=1 \mathrm{kHz}$ and damping ratio $=0.707$. It shows that the additional component $T_{1}(s)$ rises the system overshoot $(M P)$ by 5 times from the desired value which should be around $4 \%$ for 0.707 damping ratio. It can also be observed that the system has a faster response than expected. This refers to higher bandwidth which can be determined from the magnitude of the frequency response of equation (10) as shown in Fig. 5a. It shows that the system bandwidth equals $2.05 \mathrm{kHz}$ which is larger than the desired value $(1 \mathrm{kHz})$ by $105 \%$. The deviation between the desired and actual performance is considered a drawback because it refers to lower stability margins.
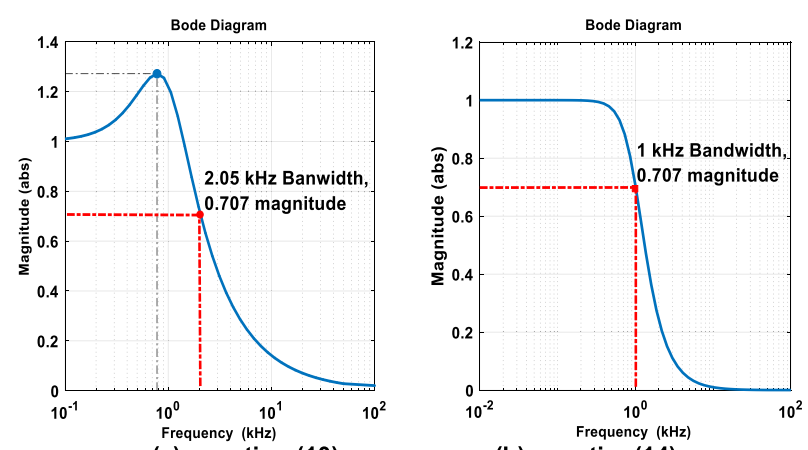

(a) equation (10)

FIGURE 5. Frequency response of closed loop transfer function.

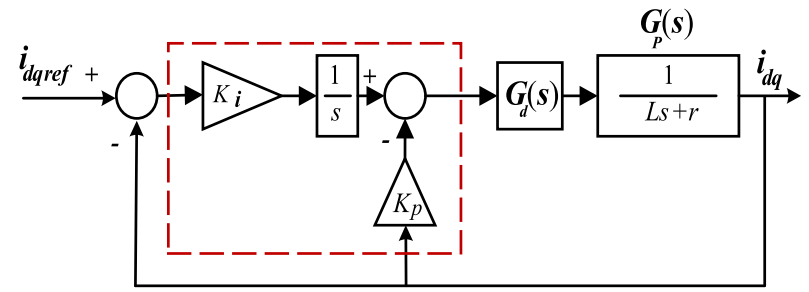

FIGURE 6. Block diagram of the current control loop using the modified conventional PI CC.

To avoid this drawback, a modification for this PI structure with the pole placement is presented in the following section [26].

\section{MODIFIED CONVENTIONAL PI CC WITH POLE PLACEMENT METHOD ( $3^{\text {rd }}$ DESIGN)}

To achieve the desired performance, whilst considering the issue described in Section II-B above, the resultant closed loop transfer function should be as given in (14).

$$
G_{c . l 3}(s)=T_{d e s}(s)=\frac{\frac{K_{i}}{L}}{s^{2}+\frac{r+K_{p}}{L} s+\frac{K_{i}}{L}}
$$

where

$$
\omega_{n}^{2}=\frac{K_{i}}{L}, \quad 2 \eta \omega_{n}=\frac{r+K_{p}}{L}
$$

As described in [26], the conventional PI CC scheme can be rearranged to that shown in Fig. 6 where the open loop transfer function (when the delay block is neglected) is expressed by (15).

$$
\therefore G_{o . l 3}(s)=\frac{T_{\text {des }}(s)}{1-T_{\text {des }}(s)}=\frac{\frac{K_{i}}{s}}{L s+r+K_{p}}
$$

It can be observed from Fig. 6 that the modified conventional PI CC is structured by using an integral part as the main controller and the proportional gain $K_{p}$ is set as an additional element in the feedback of the current. The additional element can be considered as a virtual resistance added to the machine resistance as shown from (15). So, it represents a damping element that enhances the disturbance rejection capability of the current control loop.

The modified PI scheme achieves the targeted performance as seen from Fig. 5b. It shows the magnitude of frequency 


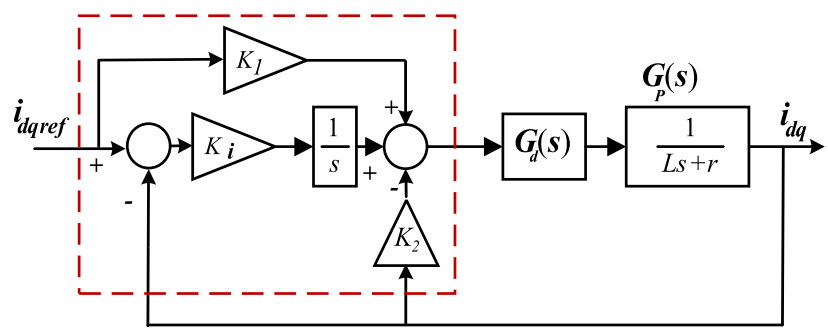

FIGURE 7. Block diagram of the current control loop using two degree of freedom PI CC.

response of equation (14) when the PI gains are tuned to achieve $1 \mathrm{kHz}$ bandwidth and 0.707 damping ratio.

Considering the delay block in Fig.6, the open and closed loop transfer functions for the current control loop can be expressed by (16) and (17) respectively. They have been used in Section III to analyze the delay effect on this CC scheme.

$$
\begin{aligned}
G_{o . l 3 d}(s) & =\frac{K_{i} G_{d}(s)}{L s^{2}+\left(r+K_{p} G_{d}(s)\right) s} \\
G_{c . l 3 d}(s) & =\frac{K_{i} G_{d}(s)}{L s^{2}+\left(r+K_{p} G_{d}(s)\right) s+K_{i} G_{d}(s)}
\end{aligned}
$$

\section{TWO DEGREE OF FREEDOM PI CC WITH POLE/ZERO CANCELATION METHOD (4 ${ }^{\text {th }}$ DESIGN)}

Another method, known as the two degree of freedom (2DOF) control is proposed to optimize the setpoint response and the disturbance response independently [27]. It provides fast disturbance rejection without a significant increase of overshoot in the step point tracking. So, it can be considered as a good option for the current control loop [14]. The 2DOF PI CC can be shown in Fig. 7. It consists of a main compensator (integral part) and two parameters $\left(K_{1}\right.$ and $\left.K_{2}\right)$ to represent feedforward and feedback terms, respectively. The control law for 2DOF PI current controller can be represented using the complex vector notation as shown by (18).

$$
u_{d q r e f}=K_{1} i_{d q r e f}+\frac{K_{i}}{s}\left[i_{d q r e f}-i_{d q}\right]-K_{2} i_{d q}
$$

Based on (18), the closed loop transfer function of the system in Fig. 7 can be expressed by (19).

$$
G_{c . l 4 d}(s)=\frac{\left(K_{1} s+K_{i}\right) G_{d}(s)}{L s^{2}+\left(r+K_{2} G_{d}(s)\right) s+K_{i} G_{d}(s)}
$$

For the open loop transfer function, due to existence of feedforward term $\left(K_{1}\right)$, it cannot be derived directly from Fig. 7. So, it is assumed that the open loop transfer function considering an augmented plant with feedback terms can be expressed as shown by (20).

$$
G_{o . l 4 d}=\frac{G_{c . l 4 d}(s)}{1-G_{c . l 4 d}(s)}
$$

To tune this CC scheme when the delay is ignored, the corresponding closed loop transfer function should be derived firstly that can be shown by (21).

$$
G_{c . l 4}(s)=\frac{\frac{K_{1}}{L} s+\frac{K_{i}}{L}}{s^{2}+\frac{r+K_{2}}{L} s+\frac{K_{i}}{L}}=\frac{a s+b}{s^{2}+c s+b}
$$

A common approach to tune $2 \mathrm{DOF} \mathrm{PI} C \mathrm{C}$ is by pole-placement to achieve pole/zero cancelation by selecting the coefficients of (21) as follows, where $\alpha$ refers to the closed loop system bandwidth (targeted bandwidth).

$$
a=\alpha, \quad b=\alpha^{2}, c=2 \alpha
$$

Accordingly, the closed loop transfer function is simplified to be a first order system as shown by (23).

$$
T(s)=\frac{\alpha}{s+\alpha}
$$

Based on (21) and (22), the controller gains can be derived as seen in (24).

$$
\left.\begin{array}{l}
K_{1}=\alpha L^{\prime} \\
K_{i}=\alpha^{2} L^{\prime} \\
K_{2}=2 \alpha L^{\prime}-r^{\prime}
\end{array}\right\}
$$

\section{ROBUSTNESS OF SRF PI CC SCHEMES TO MODULATION AND COMPUTATIONAL DELAY}

Different schemes of PI CC have been presented in Section II showing that their tuning criteria are based on one parameter, which is the targeted bandwidth $(B W)$. Hence, for same drive system and same setting of these schemes, the current response should be the same in the ideal system when the time delay is ignored.

As explained in section I, ignorance of the time delay during the PI CC design deteriorates its dynamic performance during the digital implementation. Therefore, the delay effect on the dynamic performance of the addressed PI CC schemes in Section II is studied and evaluated in this section. The robustness of each one with respect to the delay effects is analyzed to determine which CC type can achieve bandwidth close to the targeted value with less deviation in its stability margins. These margins are evaluated in frequency domain by using two performance factors, namely - phase margin $(P M)$, gain margin $(G M)$. They measure the stability degree of the stable system. For this analysis, the delay function is approximated by a second order pade expansion as shown by (25) to achieve good accuracy [28].

$$
G_{d}(s)=\frac{1-\frac{T_{d}}{2} s+\frac{T_{d}^{2}}{12} s^{2}}{1+\frac{T_{d}}{2} s+\frac{T_{d}^{2}}{12} s^{2}}
$$

The analysis of the current control system is conducted in frequency domain based on the transfer functions derived in section II. The procedure of calculating the performance factors is explained using an example of the conventional PI $\mathrm{CC}$ with pole zero cancelation method ( $1^{\text {st }}$ Design).

For the $1^{\text {st }}$ design, open and closed loop transfer functions represented in frequency domain including the delay are given by (26) and (27), as shown at the bottom of the next page, respectively.

Equations (26) and (27) are used to determine the performance factors. The phase margin is the difference between system phase angle and the verge of instability -180 at 
crossover frequency $\omega_{c}$ which can be found from the following condition:

$$
\begin{aligned}
\left|G_{o . l 1 d}\left(j \omega_{c}\right)\right| & =1 \\
\omega_{c} & =K_{o}
\end{aligned}
$$

From the resultant $\omega_{c}$, the corresponding open loop phase angle $\phi \mathrm{c}_{1}$ can be calculated as (29):

$$
\phi_{c 1}=L-90-2 \tan ^{-1} \frac{0.5 T_{d} \omega_{c}}{1-0.0833 T_{d}^{2} \omega_{c}^{2}}
$$

Then, actual phase margin of the current control loop can be found as follows:

$$
\begin{aligned}
P . M_{1} & =180+\phi_{c 1} \\
& =\angle 90-2 \tan ^{-1} \frac{0.5 T_{d} \omega_{c}}{1-0.0833 T_{d}^{2} \omega_{c}^{2}}
\end{aligned}
$$

It can be observed that the phase angle shown in (29) is a function of the delay angle which enlarges with the frequency of the input signal. Subsequently, the phase angle of the whole system increases until hits the stability limit $\left(-180^{\circ}\right)$ and sets a value of the gain margin which is defined by the open loop gain at frequency $\omega_{g}$, at which the system phase angle hits $-180^{\circ}$. Hence, this factor can be calculated from (29) as follows:

$$
\begin{aligned}
& -180=-90-2 \tan ^{-1} \frac{0.5 T_{d} \omega_{g}}{1-0.0833 T_{d}^{2} \omega_{g}^{2}} \\
& \therefore \omega_{g}=\frac{1.58}{T_{d}}
\end{aligned}
$$

The frequency $\omega_{g}$ can also be evaluated using the exact delay model represented by (2) as follows:

$$
\begin{aligned}
-180 & =-90-\omega T_{d} \\
\therefore \omega_{g} & =\frac{1.571}{T_{d}}
\end{aligned}
$$

From (31) and (32), it can be concluded that the second order pade expansion (25) provides good approximation for the exact delay model (2).

From (31), the gain margin can be calculated using the equation for magnitude (27) as follows:

$$
G . M=-20 \log \left(\frac{K_{o}}{\omega_{g}}\right)
$$

The actual system bandwidth $\omega_{b 1}$ can be calculated from equation (27) as the point at which the absolute value of the closed loop transfer function equals 0.707 .

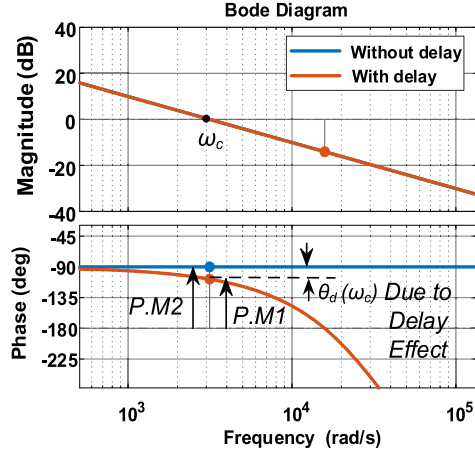

(a) Open loop function

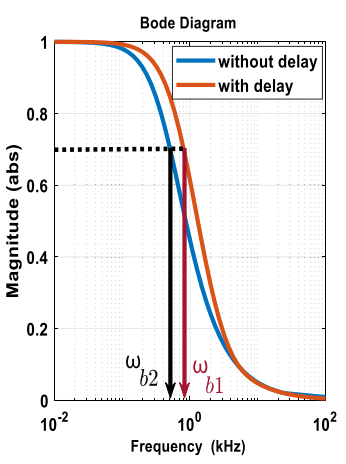

(b) Closed loop function
FIGURE 8. Frequency response of the current loop transfer functions.

In case of the delay ignorance, it can be seen from (29) that the system's phase angle at $T_{d}=0$ has fixed value $-90^{\circ}$. So, the open loop angle does not hit the stability limit $-180^{\circ}$. Consequently, it can be deduced that the system has infinite gain margin.

The aforementioned factors can be explained from Fig. 8 that shows the frequency response obtained by using MATLAB software for open and closed loop functions of $1^{\text {st }}$ design at targeted bandwidth equals $500 \mathrm{~Hz}$ and switching frequency equals $15 \mathrm{kHz}$.

Similar to the analysis above, the performance factors have been calculated for other CCs $\left(2^{\text {nd }}, 3^{\text {rd }}\right.$, and $4^{\text {th }}$ designs $)$. Subsequently, the effect of delay on the system bandwidth is determined using equations (34), where $B W$ refers to the targeted bandwidth and $B W_{l}=\omega_{b l}$ for the actual bandwidth (expected after the practical implementation).

$$
\Delta B W=B W_{1}-B W
$$

The changes in control loop bandwidth and performance factors $(P M$ and $G M)$ are calculated at different values of the targeted bandwidth. The results are shown in Fig. 9 at two different switching frequencies 10 and $20 \mathrm{kHz}$ (refers to two different delay levels). It can be shown from Fig. 9 that the change of bandwidth has a positive sign and corresponding to (34), it can be deduced that the delay enlarges the system bandwidth. Moreover, it can be observed that phase and gain margins decrease at higher sets of the targeted bandwidth. These effects show the negative impact of the delay on system dynamics especially when high bandwidth is required. Consequently, the desired bandwidth should be chosen in order to achieve reasonable values of the stability margins after

$$
\begin{aligned}
G_{o . l 1 d}(j \omega) & =\frac{K_{0}}{\omega} L-90-2 \tan ^{-1} \frac{0.5 T_{d} \omega}{1-0.0833 T_{d}^{2} \omega^{2}} \\
\left|G_{c . l 1 d}(j \omega)\right| & =\frac{\sqrt{\left(1-0.0833 T_{d}^{2} \omega^{2}\right)^{2}+\left(0.5 T_{d} \omega\right)^{2}}}{\sqrt{\left(-0.5 T_{d} \omega^{2}+K_{o}-0.0833 T_{d}^{2} \omega^{2} K_{o}\right)^{2}+\omega\left(1-0.0833 T_{d}^{2} \omega^{2}-0.5 T_{d} K_{o}\right)^{2}}}
\end{aligned}
$$



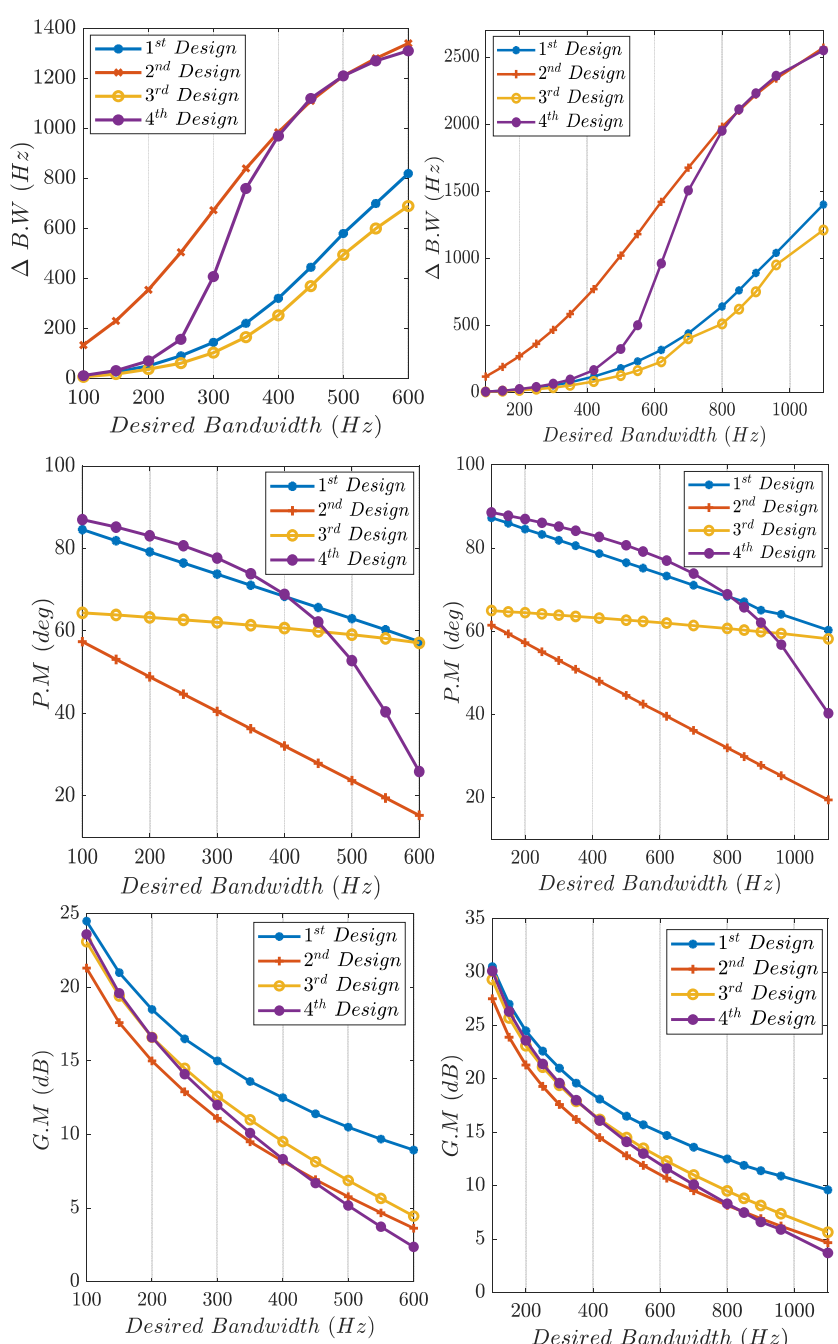

(a) At fsw=10 kHz

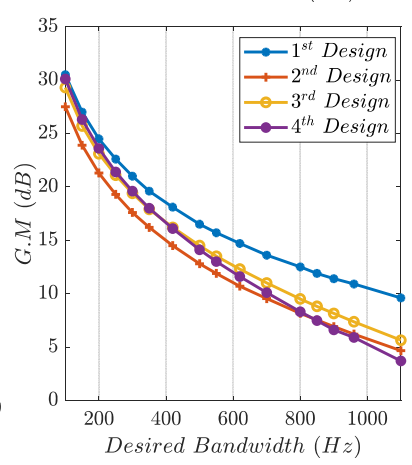

(b) At fsw $=20 \mathrm{kHz}$

FIGURE 9. Performance parameters of current control loop using the frequency response analysis at different switching frequencies.

considering the delay effect, phase margin $40-55^{\circ}$ and gain margin 5-6 dB [19], [29].

These margins can be checked by the transfer functions derived in Section II. However, it should be mentioned that, in the current control system of ac machines, there are additional factors that degrade system performance during the operation such as the operating frequency, parameters variation [8], [30], [31]. These factors degrade the system stability during the operation. So, it would be better to tune the $\mathrm{CCs}$ to achieve higher stability margins, phase margin $55-65^{\circ}$ and gain margins $7-10 \mathrm{~dB}$, to achieve reasonable performance during the machine operation.

For robustness of the $\mathrm{CC}$ schemes to the delay effects, from Fig. 9, it can be observed that the minimum change in the current loop system bandwidth happens with the $1^{\text {st }}$ and $3^{\text {rd }}$ designs. For $2^{\text {nd }}$ and $4^{\text {th }}$ designs, the actual system bandwidth is significantly different than its desired value especially for higher bandwidth sets. Consequently, it can be stated that the

TABLE 2. Delay margins formulas.

\begin{tabular}{|c|c|}
\hline CC SCHEME & Delay Margin $\left(T_{d_{-} \text {margin }}\right)$ \\
\hline $1^{\text {st }}$ Design & $T_{d_{-} \operatorname{margin}}=\frac{2}{K_{o}}$ \\
\hline $\begin{array}{l}2^{\text {nd }} \text { Design } \\
\text { and } \\
3^{\text {rd }} \text { Design }\end{array}$ & $\begin{array}{c}T_{d \_ \text {margin }}=\frac{-y+\sqrt{y^{2}+4 x z}}{2 x} \\
x=0.25 K_{i}\left(r-K_{p}\right), y=K_{i} L-0.5\left(r^{2}-K_{p}^{2}\right) \\
z=-\left(r+K_{p}\right) L\end{array}$ \\
\hline $4^{\text {th }}$ Design & $\begin{array}{c}T_{d \_ \text {margin }}=\frac{-y+\sqrt{y^{2}+4 x z}}{2 x} \\
x=0.25 K_{i}\left(r-K_{2}\right), y=K_{i} L-0.5\left(r^{2}-K_{2}^{2}\right) \\
z=-\left(r+K_{2}\right) L\end{array}$ \\
\hline
\end{tabular}

$1^{\text {st }}$ and $3^{\text {rd }}$ designs have the highest robustness to the delay effect compare to other PI CC schemes.

It can also be noticed that the $1^{\text {st }}$ design has the lowest sensitivity to the targeted bandwidth in terms of the stability effects. It provides better stability margins which refer to better dynamic performance when the bandwidth is set at higher values. On the other hand, the $2^{\text {nd }}$ design is very sensitive to higher bandwidth sets where its stability margins are significantly affected.

As further investigation to differentiate between the dynamic performances of the addressed PI CCs for same electric drive system (same switching frequency which refers to the time delay) and same targeted bandwidth, the concept of delay margin is used to define the maximum time delay that the system can tolerate before going unstable. The formulae to define the delay margin can be derived from Routh stability criterion. The time delay in this derivation is approximated by $1^{\text {st }}$ order Pade approximation (35).

$$
G_{d}(s)=\frac{1-0.5 T_{d} s}{1+0.5 T_{d} s}
$$

It should be noted that the $1^{\text {st }}$ order model for the delay does not provide the same approximation accuracy as $2^{\text {nd }}$ order one this has been used in the previous section. However, the aim of this section to define which CC design can provide a higher delay margin but not to derive an exact delay margin value, i.e., it just represents as an indication factor for the performance comparison, which justifies the acceptance of using simpler $1^{\text {st }}$ order model. The delay margin formula for each CC is derived and summarized in Table 2 where $2^{\text {nd }}$ and $3^{\text {rd }}$ schemes have the same delay margin as they have similar characteristic equations.

The changes of delay margin at different values of the targeted bandwidth $B W$ are shown in Fig. 10. It shows that the $1^{\text {st }}$ design has largest delay margin at same targeted bandwidth. Accordingly, for the same targeted bandwidth and same switching frequency, $1^{\text {st }}$ design can provide better stability margins than other CCs. For the other CC schemes, the delay margin of the $3^{\text {rd }}$ design is slightly better than $4^{\text {th }}$ design. These observations from the delay margin study show that the chosen targeted bandwidth for tuning $2^{\text {nd }}, 3^{\text {rd }}$ and $4^{\text {th }}$ schemes should be lower than the value used for the $1^{\text {st }}$ design if same stability margins need to be achieved. 


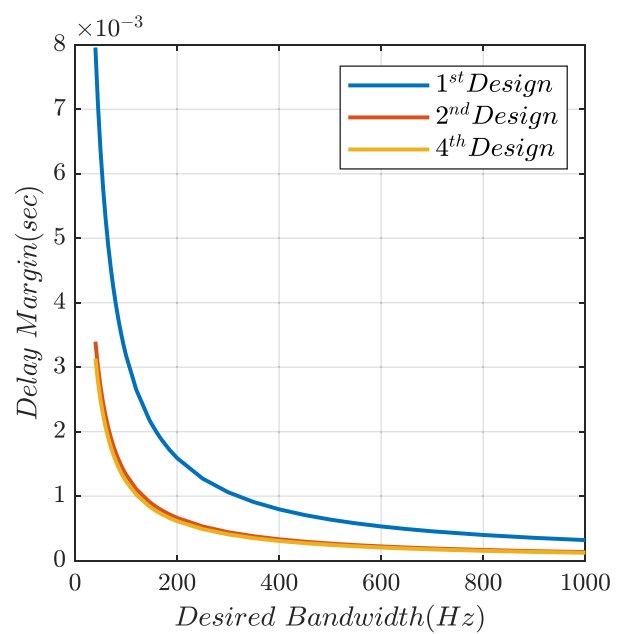

FIGURE 10. Delay Margin change with the desired bandwidth for different types of the CCs.

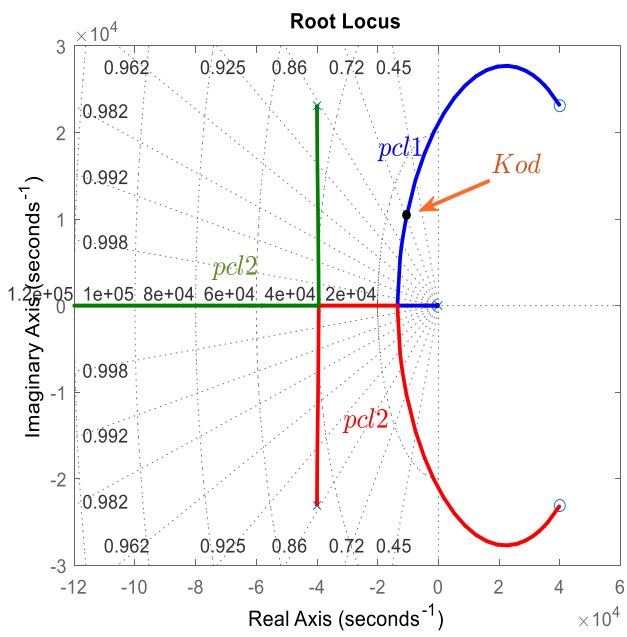

FIGURE 11. Root locus of (36) at $20 \mathrm{kHz}$ switching frequency.

Moreover, the targeted bandwidth used for $4^{\text {th }}$ design should be slightly lower than its value for the $3^{\text {rd }}$ design to have same stability margins. These results provide good understanding for tuning these schemes and they have been used to develop a generic recommendation for tuning the PI CCs as presented in Section IV.

\section{PROPOSED DESIGN RECOMMENDATIONS}

The results on Section III show the delay effect on the addressed PI CC schemes and their sensitivity to the targeted bandwidth value used in the tuning process. Accordingly, targeted bandwidth should be carefully chosen to achieve reasonable dynamic performance. To simplify this process, generic formulas have been presented in this section taking the delay effects into account.

For the $1^{\text {st }}$ design, the controller gain $K_{O}$ (refers to the targeted bandwidth $(B W)$ ) in the conventional PI CC with pole zero cancellation can be tuned considering the delay effect based on the root locus of the open loop transfer function represented by (36), where the delay model is represented

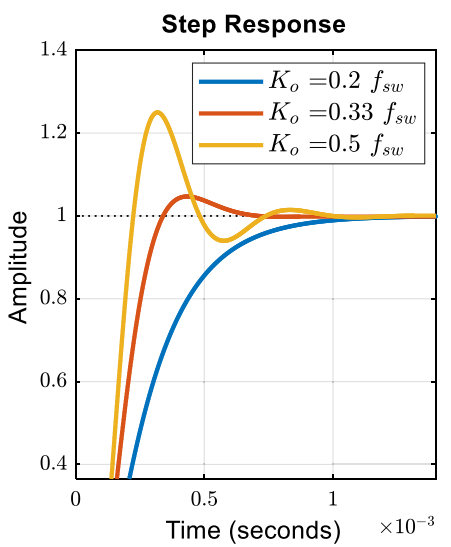

FIGURE 12. Step response using (7) at $16 \mathrm{kHz}$ switching frequency with different controller settings for $1^{\text {st }}$ design $\mathrm{CC}$.

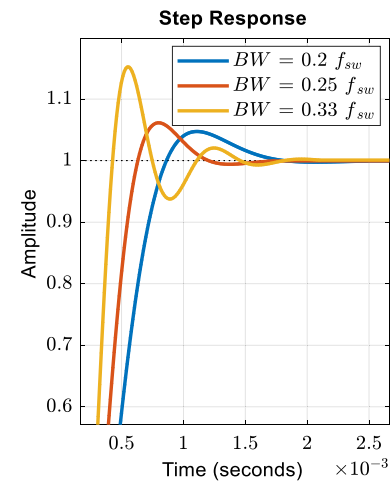

(a) $3^{\text {rd }}$ design

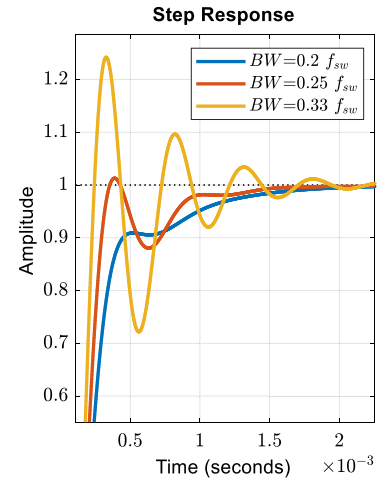

(b) $4^{\text {th }}$ design
FIGURE 13. Step response at $16 \mathbf{~ k H z}$ switching frequency with different controller settings for $3^{\text {rd }}$ and $4^{\text {th }}$ design using (17) and (19) respectively.
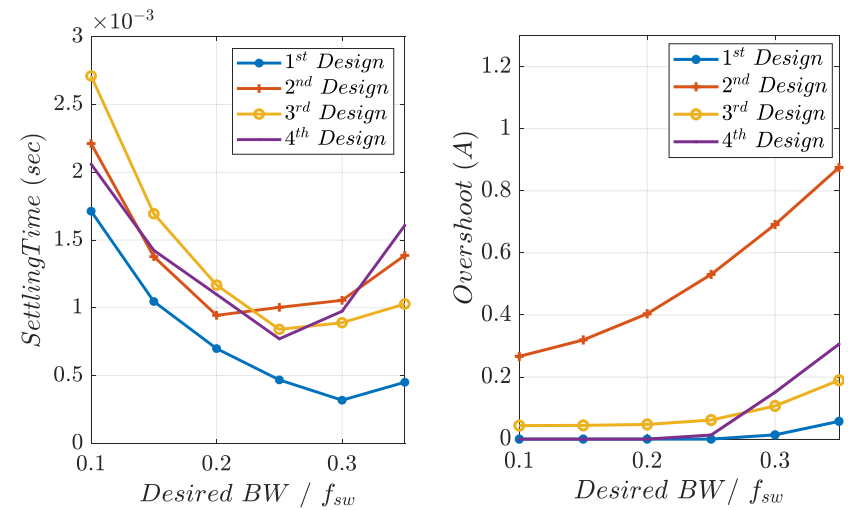

FIGURE 14. Overshoot and settling time versus the ratio between the desired bandwidth and switching frequency.

by (25) in (6) as follows:

$$
G_{o . l 1 d}(s)=K_{o} \frac{1-\frac{T_{d}}{2} s+\frac{T_{d}^{2}}{12} s^{2}}{\mathrm{~s}+\frac{T_{d}}{2} s^{2}+\frac{T_{d}^{2}}{12} s^{3}}
$$

The root locus of (37) can be shown in Fig. 11 at $20 \mathrm{kHz}$ switching frequency. It can be observed that the current control system has three closed loop poles where $p_{c l 1}$ and $p_{c l 2}$ are considered the dominant poles as the stability margins 
TABLE 3. Design guidelines of SRF PI CC schemes.

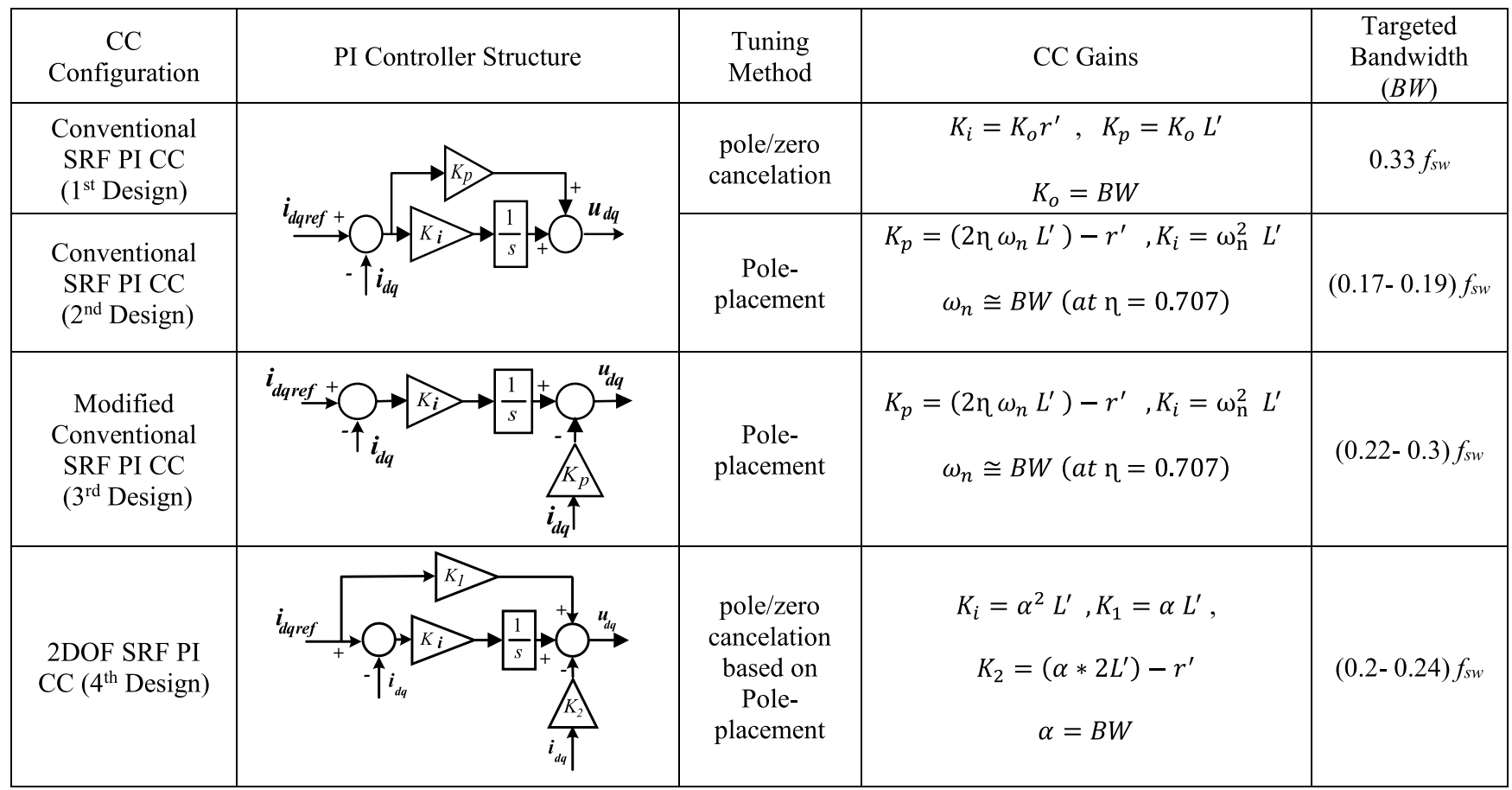

are determined from their real parts when the value of $K_{o}$ increases. Subsequently, the controller gain can be tuned using the location of $p_{c l 1}$ and $p_{c l 2}$ to achieve a certain performance.

In order to achieve the strongest disturbance rejection possible with negligible overshoot, the controller should be tuned in order to have an optimal damping ratio $(\eta=0.707)$ [23]. The proposed setting $\left(K_{o d}\right)$ can be derived analytically from the symbolic solution for the roots of the characteristic equation (37).

$$
T_{d}^{2} s^{3}+\left(6 T_{d}+K_{o} T_{d}^{2}\right) s^{2}+\left(12-6 K_{o} T_{d}\right) \mathrm{s}+12 K_{o}=0
$$

The general expressions for the closed loop poles are shown by (38) and (39) [9] as a solution of (37), where $f_{s w}$ is the switching frequency $\left(f_{s w}=1 / T_{s w}\right)$.

$$
\begin{aligned}
p_{c l 1,2} \cong \frac{1}{6}\left\{\begin{array}{c}
\beta\left[-\beta-2\left(K_{o}+4 f_{s w}\right)-\beta^{2}\left(K_{o}^{2}-20 f_{s w} K_{o}\right)\right] \\
\mp j\left[\sqrt{3} \beta^{2}-\beta^{3}\left(K_{o}^{2}-20 f_{s w} K_{o}\right)\right]
\end{array}\right\} \\
p_{c l 3}=\frac{1}{3}\left[\beta^{2}-\beta\left(K_{o}+4 f_{s w}\right)+\beta^{3}\left(K_{o}^{2}+20 f_{s w} K_{p}\right)\right]
\end{aligned}
$$

where

$$
\begin{aligned}
& \beta=2 f_{s w} \sqrt{\sigma}-K_{o}^{3}-30 f_{s w} K_{o}^{2}-168 f_{s w}^{2} K_{o}+32 f_{s w}^{3} \\
& \sigma=9 K_{o}^{4}+504 f_{s w} K_{o}^{3}+6576 f_{s w}^{2} K_{o}^{2}-2688 f_{s w}^{3} K_{o}+256 f_{s w}^{4}
\end{aligned}
$$

At 0.707 damping ratio, the real and imaginary parts of $p_{c l 1}$ and $p_{c l 2}$ are equal. Therefore, a generic formula for the
TABLE 4. Discretization methods.

\begin{tabular}{|c|c|}
\hline Backword Difference Method & $s=\frac{1}{T_{S}}\left(1-z^{-1}\right)$ \\
\hline Forward Difference Method & $s=\frac{1}{T_{s}}\left(\frac{1-z^{-1}}{z^{-1}}\right)$ \\
\hline Tustin (Trapazoidal) Method & $s=\frac{2}{T_{s}}\left(\frac{1-z^{-1}}{1+z^{-1}}\right)$ \\
\hline
\end{tabular}

controller gain $K_{o}$ can be expressed by (40) from equalizing the real and imaginary parts of (38).

$$
K_{o d} \cong 0.33 f_{s w}
$$

Considering that $f_{s w}=1.5 / T_{d}$, the gain and phase margin corresponding to the proposed setting (40) can be evaluated using (30) and (33) from Section II. Accordingly, it can be found that gain and phase margins are $10.1 \mathrm{~dB}$ and $61.64^{\circ}$, respectively. These values guarantee to have acceptable dynamic performance as shown from the step response in Fig. 12 at different values of $k_{o}$ which has been selected as a ratio of the switching frequency.

For the other PI CCs $\left(2^{\text {nd }}, 3^{\text {rd }}\right.$ and $\left.4^{\text {th }}\right)$, their targeted bandwidth should be lower than $33 \%$ of the switching frequency to provide reasonable performance according to study of their stability margins and delay margins compared to $1^{\text {st }}$ design shown in Section III. 


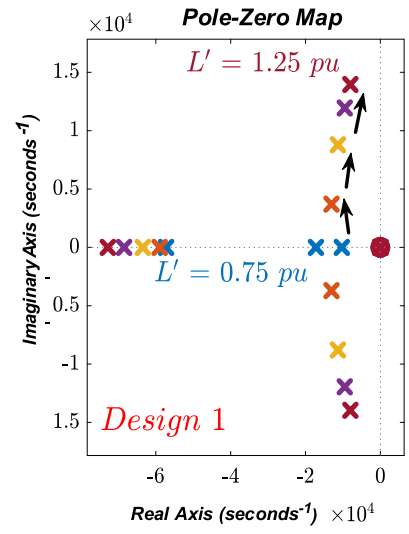

(a) $1^{\text {st }}$ Design (BW=0.33 $\left.f_{\text {sw }}\right)$

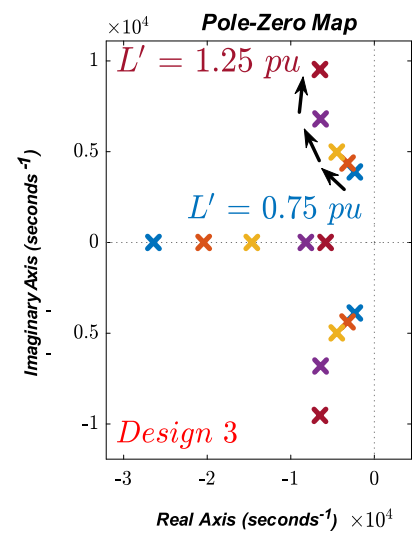

(c) $3^{\text {rd }}$ Design (BW=0.22 $\left.f_{s w}\right)$

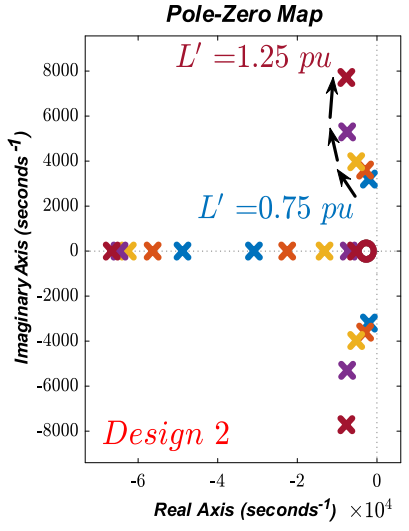

(b) $2^{\text {nd }}$ Design (BW=0.17 $\left.f_{s w}\right)$

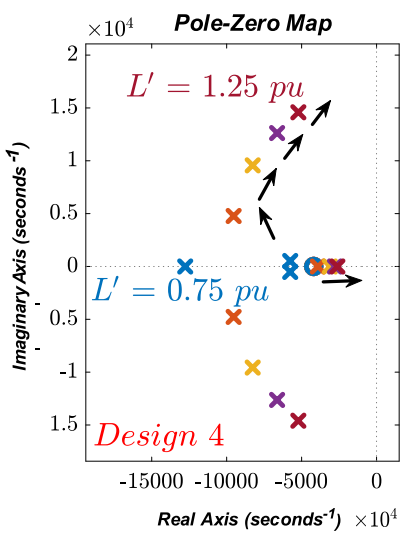

(d) $4^{\text {th }}$ Design $\left(B W=0.21 f_{s w}\right)$

FIGURE 15. Dominant eigenvalues migration of current control loop with different inductance sets in the controller's parameters.

From Fig. 9, the stability margins $(G M=10.1 \mathrm{~dB}$ and $P M=61.64^{\circ}$ ) can be achieved with the $3^{\text {rd }}$ design when its targeted bandwidth set at around $75-85 \%$ of the targeted bandwidth of the $1^{\text {st }}$ design. Consequently, the targeted bandwidth of $3^{\text {rd }}$ design can be set at $22-30 \%$ of the drive switching frequency to achieve reasonable dynamic performance. For the $2^{\text {nd }}$ design, the chosen targeted bandwidth should be lower than the used in the $3^{\text {rd }}$ design due to the zero effect.

For the $4^{\text {th }}$ design, it can be shown from Fig. 9 that it has a lower gain margin than the $1^{\text {st }}$ and $3^{\text {rd }}$ designs. Moreover, the delay margin of the $4^{\text {th }}$ design is slightly lower than the $3^{\text {rd }}$ design as discussed in Section III. Accordingly, its targeted bandwidth can be around $67 \%$ of the proposed ratio for the $1^{\text {st }}$ design. Hence, it can be stated that the $4^{\text {th }}$ design can be tuned for targeted bandwidth ( $\alpha$ in $\mathrm{rad} / \mathrm{s}$ ) equals $20-24 \%$ of the drive switching frequency. The step response of the current control loop at $16 \mathrm{kHz}$ switching frequency with $3^{\text {rd }}$ and $4^{\text {th }}$ designs is shown in Fig.13 using the recommended tuning ratios.

The performance factors (overshoot and settling time) for the addressed controllers have been also determined and reported in Fig. 14 at different bandwidth settings. The results show the ability of the $1^{\text {st }}$ design to provide faster dynamics

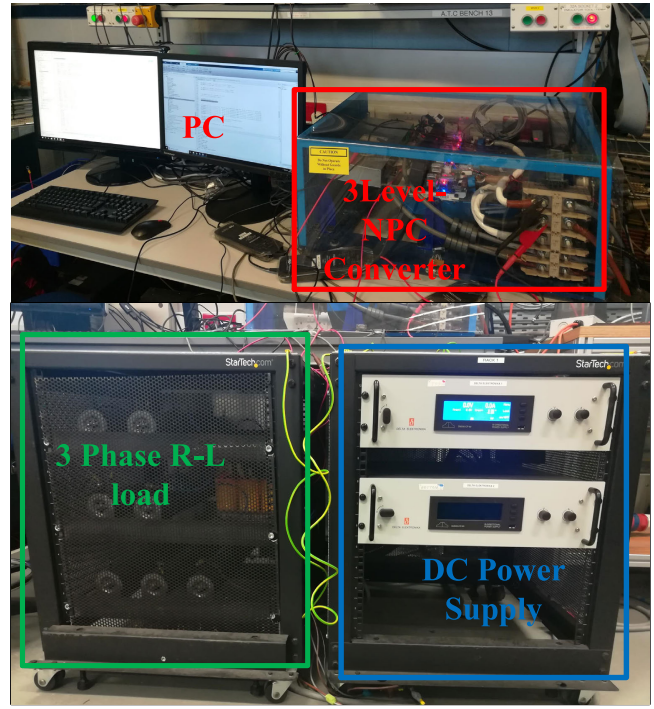

FIGURE 16. Experimental set up.

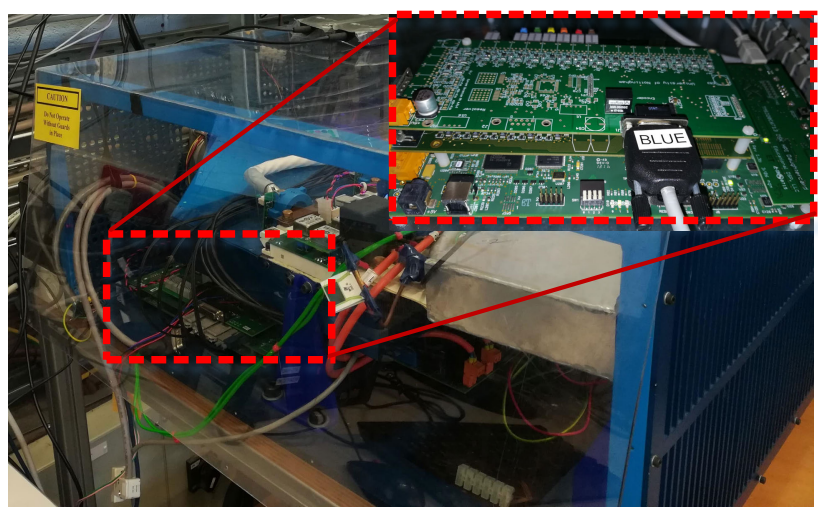

FIGURE 17. Inverter and control platform (texas instrument, TMS320C6713 DSP starter kit).

with lower overshoot compared to the other designs. Moreover, it can be noticed that minimum settling time with the $3^{\text {rd }}$ and $4^{\text {th }}$ design occurs within the recommended setting which validates the analysis in Section III. To conclude the addressed PI CC schemes and their design recommendations for the gains' selection, they have been summarized in Table 3.

\section{ROBUSTNESS TO MODEL UNCERTAINTIES}

Tuning guidelines shown in Table 3 depend on the system parameters namely, resistance and inductance values which might be slightly different than their actual values. Therefore, the effects of these uncertainties on the system stability are studied in this section through the analysis of the systems' eigenvalues.

Effects of inductance uncertainties can be shown in Fig. 15. It shows the current control system's eigenvalues when the inductance value used in the controller design has $\pm 25 \%$ error. It can be observed from the eigenvalues migration that the proposed design recommendations guarantee system stability even with wide errors in the inductance value. It can also be shown from Fig. 15 that the eigenvalues move away 
Design 1

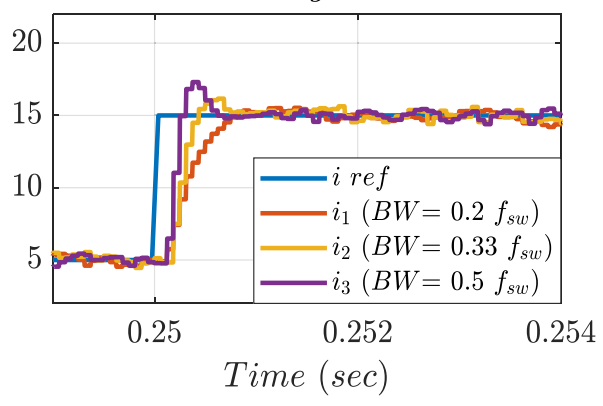

Design 3

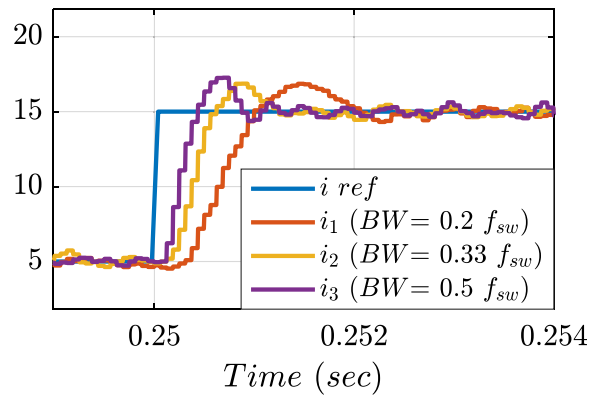

Design 2

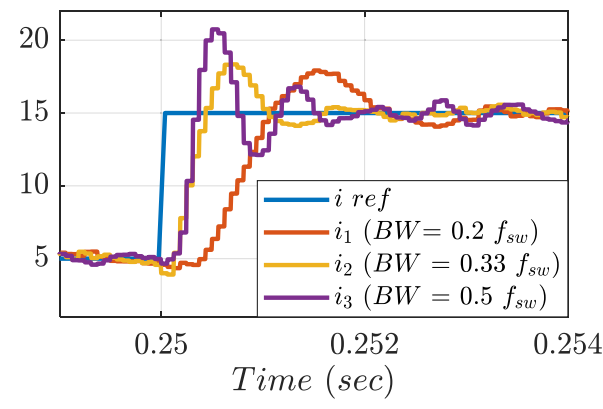

Design 4

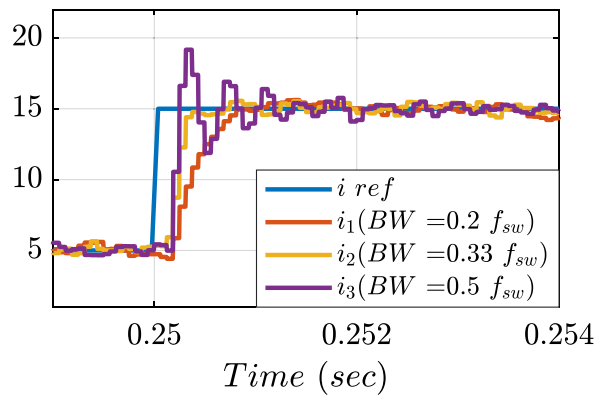

FIGURE 18. Experimental current responses at different controller's settings.

from the real axis at higher inductance sets. Hence, the system bandwidth increases to achieve faster step response.

For the resistance uncertainties, normally the machine resistance increases due to the system heating. As the machine resistance represents a damping element, the system stability margins improve, and the system response becomes slower with lower overshoot. This phenomenon is similar to setting the resistance in the controller to be lower than its actual value [32].

\section{EXPERIMENTAL RESULTS}

The proposed design recommendations and the analytical studies in this paper have been validated using experimental test rig shown in Fig.16. A three phase R-L load ( $r=5 \mathrm{ohm}$, $L=1 \mathrm{mH}$ ) has been used to simulate the three-phase rotating machine and to void the unwanted torque effects [16]. The $\mathrm{R}-\mathrm{L}$ load is supplied from three level neutral point clamped converter (NPC) at $16 \mathrm{kHz}$ switching frequency. The PI CCs shown in Table 3 have been digitally implemented in a digital signal processor (DSP) (Texas Instrument, TMS320C6713 DSP Starter Kit shown in Fig. 17 using code composer software (CCS). For the digital implementation, discretization of the continuous CCs is required. Various methods can be used to convert the continuous system into an equivalent discrete-time system. However, it should be noted, that the continuous system can only be approximated, and the discrete system can never be exactly equivalent. Different methods can result different controller performances. The most important methods are summarized in Table 4 [28], [33]. Among these methods, Tustin transformation is considered the most commonly used method as it allows to maintain same stability properties in both s- and z-domain [28], [34], [35]. Consequently, it has been used to discretize the continuous PI CCs for digital implementation. The dynamic performance of the CCs has been tested by a step response of a $10 \mathrm{~A}$ as a reference q-current component.

\section{A. ROBUSTNESS TO DELAY EFFECTS}

The performance dynamics of PI CCs shown in Table 3 have been tested at $350 \mathrm{~Hz}$ fundamental frequency as shown in Fig. 18. The desired bandwidth $(B W)$ for all PI CCs is selected as a ratio of the drive switching frequency to verify the proposed design recommendations in Section IV and to evaluate the robustness of the PICC schemes to the time delay effects.

Firstly, it can be seen from Fig. 18 that the $3^{\text {rd }}$ design provides more stable response ( less oscillations and lower overshoot) than the $2^{\text {nd }}$ design at same settings which verify the preference of the modified PI structure $\left(3^{\text {rd }}\right.$ design) as discussed in Section II.

It can also be observed that, at high $B W$ values, the degradation of the transient response is high with the $2^{\text {nd }}$ and $4^{\text {th }}$ design compared to $1^{\text {st }}$ and $3^{\text {rd }}$ designs. These results refer to higher deterioration in the stability margins of the $2^{\text {nd }}$ and $4^{\text {th }}$ designs compared to the $1^{\text {st }}$ and $3^{\text {rd }}$ designs. The findings from these test results are matching with the analytical results in section III for the frequency response analysis which show the higher robustness of the $1^{\text {st }}$ and $3^{\text {rd }}$ designs for delay effect. Moreover, it can also be observed that the $1^{\text {st }}$ design provides faster dynamics with better stability margins 

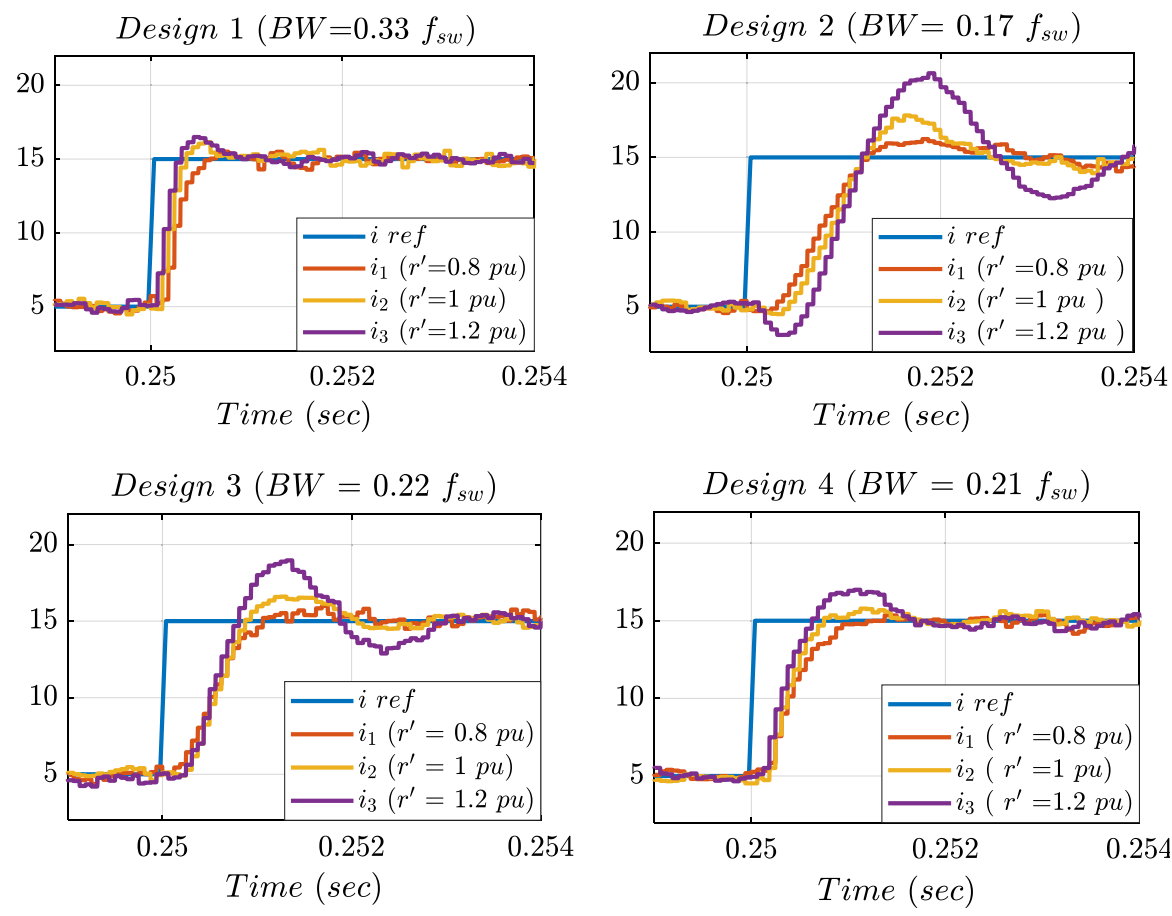

FIGURE 19. Experimental current responses at different resistance values in controller setting.
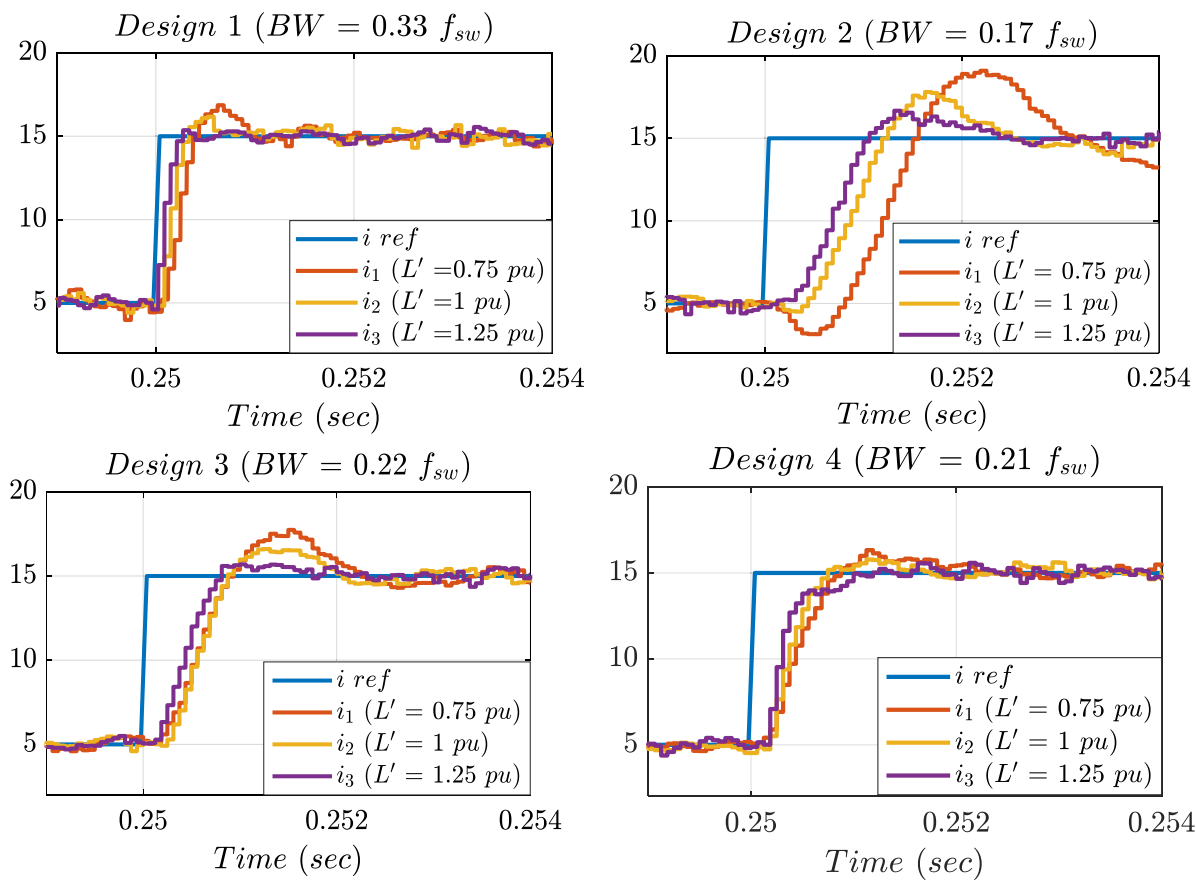

FIGURE 20. Experimental current responses at different inductance values in controller setting.

compared to other CCs at higher bandwidth settings which validates the delay margin study in Section III.

The results also show that the CCs provides reasonable dynamics in terms of negligible overshoot with fast response when the proposed design recommendations in Table 3 are used. These results validate the proposed setting in Section IV which can be used as a fast and simple tuning tool in the industry. The results also show that higher setting for the desired bandwidth degrades the system stability and affects the system performance.

\section{B. ROBUSTNESS TO MODEL UNCERTAINTIES}

The robustness of PI CCs to the model uncertainties has been tested when the proposed design recommendations are used. 
It is assumed that there are errors in the system parameters (resistance and inductance) used in the controller's setting. The effects of resistance and inductance uncertainties on the system dynamics are tested as shown in Fig. 19 and Fig. 20, respectively. For the resistance effects, it is assumed that there are $\pm 20 \%$ error in the resistance value used in the controller setting. The experimental results show that the design recommendations provide reasonable dynamics with large errors in the system resistance. The results also show that lower resistance setting enlarge the damping ratio as it is similar to the case of heating the machine.

For the inductance errors, it is assumed that there are $\pm 25 \%$ errors for the inductance value used in the controller setting. The results in Fig. 20 show that the design recommendations guarantee higher stability margins for the addressed CCs during the tuning process with wide errors in the inductance value. It can be also be observed that higher inductance settings provides faster step response which validates the eigenvalues study in Section V. The results also show that the $1^{\text {st }}$ design provides high robustness to the model uncertainties compared to other schemes which can be interpreted by its high stability margins shown in Section III and V.

\section{CONCLUSION}

This paper investigated different tuning configurations of the SRF PI CCs which have not considered the delay effect on their tuning rules. The paper also analyzed and evaluated the effect of computational and modulation delays on their dynamic performance. Generic recommendations for tuning these PI CCs, which are summarized in Table 3, have been proposed as a function of the drive system's switching frequency.

It can be concluded that the classical PI controller tuned by pole zero cancelation method $\left(1^{\text {st }}\right.$ design $)$ provides the highest robustness to the delay effects in terms of achieving the targeted bandwidth with higher stability margins. It is advised to set its gain (targeted bandwidth $(B W)$ ) at $33 \%$ of the drive system's switching frequency. The proposed setting achieves gain and phase margins equal $10.1 \mathrm{~dB}$ and $61.64^{\circ}$ respectively which provides fast dynamic response with negligible overshoot corresponding to 0.707 damping ratio. For the modified PI controller tuned by pole placement ( $3^{\text {rd }}$ design), it is advised to set its targeted bandwidth at 22-30\% of the drive switching frequency whereas this ratio is $20-24 \%$ for the 2DOF PI controller with pole placement method ( $4^{\text {th }}$ design). These settings guarantee reasonable dynamic performance for the addressed CCs and represent fast and simple tuning rules for the electric drives in the industry. These claims have been validated through experiments.

\section{REFERENCES}

[1] D. G. Holmes, B. P. McGrath, and S. G. Parker, "Current regulation strategies for vector-controlled induction motor drives," IEEE Trans. Ind. Electron., vol. 59, no. 10, pp. 3680-3689, Oct. 2012.

[2] M. Kadjoudj, M. E. H. Benbouzid, C. Ghennai, and D. Diallo, "A robust hybrid current control for permanent-magnet synchronous motor drive,' IEEE Trans. Energy Convers., vol. 19, no. 1, pp. 109-115, Mar. 2004
[3] A. M. Diab, S. Bozhko, M. Galea, and C. Gerada, "Stable and robust design of active disturbance-rejection current controller for permanent magnet machines in transportation systems," IEEE Trans. Transport. Electrific., vol. 6, no. 4, pp. 1421-1433, Dec. 2020.

[4] S. S. Yeoh, T. Yang, L. Tarisciotti, C. I. Hill, S. Bozhko, and P. Zanchetta, "Permanent-magnet machine-based starter-generator system with modulated model predictive control," IEEE Trans. Transport. Electrific., vol. 3, no. 4, pp. 878-890, Dec. 2017.

[5] A. A. Abdelrauf, W. W. Saad, A. Hebala, and M. Galea, "Model predictive control based PID controller for PMSM for propulsion systems," in Proc. IEEE Int. Conf. Electr. Syst. Aircr., Railway, Ship Propuls. Road Vehicles Int. Transp. Electrific. Conf. (ESARS-ITEC), Nov. 2018, pp. 1-7.

[6] F. D. Freijedo, A. Vidal, A. G. Yepes, J. M. Guerrero, O. Lopez, J. Malvar, and J. Doval-Gandoy, "Tuning of synchronous-frame PI current controllers in grid-connected converters operating at a low sampling rate by MIMO root locus," IEEE Trans. Ind. Electron., vol. 62, no. 8, pp. 5006-5017, Aug. 2015.

[7] J. Holtz, J. Quan, J. Pontt, J. Rodriguez, P. Newman, and H. Miranda, "Design of fast and robust current regulators for high-power drives based on complex state variables," IEEE Trans. Ind. Appl., vol. 40, no. 5, pp. 1388-1397, Sep. 2004.

[8] F. Briz and M. Hinkkanen, "Design, implementation and performance of synchronous current regulators for AC drives," Chin. J. Electr. Eng., vol. 4, no. 3, pp. 53-65, 2018.

[9] A. G. Yepes, A. Vidal, J. Malvar, O. López, and J. Doval-Gandoy, “Tuning method aimed at optimized settling time and overshoot for synchronous proportional-integral current control in electric machines," IEEE Trans. Power Electron., vol. 29, no. 6, pp. 3041-3054, Jun. 2014.

[10] F. Briz, M. W. Degner, and R. D. Lorenz, "Analysis and design of current regulators using complex vectors," IEEE Trans. Ind. Appl., vol. 36, no. 3, pp. 817-825, May/Jun. 2000.

[11] J. Jung and K. Nam, "A dynamic decoupling control scheme for high-speed operation of induction motors," IEEE Trans. Ind. Electron., vol. 46, no. 1, pp. 100-110, Feb. 1999.

[12] K. Lee and J.-I. Ha, "Dynamic decoupling control method for PMSM drive with cross-coupling inductances," in Proc. IEEE Appl. Power Electron. Conf. Expo. (APEC), Mar. 2017, pp. 563-569.

[13] B.-H. Bae and S.-K. Sul, "A compensation method for time delay of fulldigital synchronous frame current regulator of PWM AC drives," IEEE Trans. Ind. Appl., vol. 39, no. 3, pp. 802-810, May 2003.

[14] M. Hinkkanen, H. A. A. Awan, Z. Qu, T. Tuovinen, and F. Briz, "Current control for synchronous motor drives: Direct discrete-time pole-placement design," IEEE Trans. Ind. Appl., vol. 52, no. 2, pp. 1530-1541, Apr. 2016.

[15] S. Bozhko, S. S. Yeoh, F. Gao, and C. Hill, "Aircraft starter-generator system based on permanent-magnet machine fed by active front-end rectifier," in Proc. 40th Annu. Conf. IEEE Ind. Electron. Soc. (IECON), Oct. 2014, pp. 2958-2964.

[16] F. B. D. Blanco, M. W. Degner, and R. D. Lorenz, "Dynamic analysis of current regulators for AC motors using complex vectors," IEEE Trans. Ind. Appl., vol. 35, no. 6, pp. 1424-1432, Nov./Dec. 1999.

[17] W. K. Ho, O. P. Gan, E. B. Tay, and E. L. Ang, "Performance and gain and phase margins of well-known PID tuning formulas," IEEE Trans. Control Syst. Technol., vol. 4, no. 4, pp. 473-477, Jul. 1996.

[18] B. C. Kuo, Automatic Control System. London, U.K.: Prentice-Hall, 1962.

[19] D. G. Holmes, T. A. Lipo, B. P. McGrath, and W. Y. Kong, "Optimized design of stationary frame three phase AC current regulators," IEEE Trans. Power Electron., vol. 24, no. 11, pp. 2417-2426, Nov. 2009.

[20] M. Comanescu and T. Batzel, "Design of current controllers in sensorless induction motor applications-Speed control versus torque control," in Proc. Int. Aegean Conf. Electr. Mach. Power Electron., Sep. 2007, pp. 425-429.

[21] N. Hoffmann, F. W. Fuchs, M. P. Kazmierkowski, and D. Schröder, "Digital current control in a rotating reference frame-Part I: System modeling and the discrete time-domain current controller with improved decoupling capabilities," IEEE Trans. Power Electron., vol. 31, no. 7, pp. 5290-5305, Jul. 2016.

[22] Y. Liao, F. Li, H. Lin, and J. Zhang, "Discrete current control with improved disturbance rejection for surface-mounted permanent magnet synchronous machine at high speed," IET Electr. Power Appl., vol. 11, no. 7, pp. 1333-1340, Aug. 2017.

[23] C. H. Van Der Broeck, S. A. Richter, J. V. Bloh, and R. W. De Doncker, "Methodology for analysis and design of discrete time current controllers for three-phase PWM converters," CPSS Trans. Power Electron. Appl., vol. 3 , no. 3 , pp. $254-264$, Sep. 2018. 
[24] P. Cominos and N. Munro, "PID controllers: Recent tuning methods and design to specification," IEE Proc., Control Theory Appl., vol. 149, no. 1, pp. 46-53, Jan. 2002.

[25] V. Blasko and V. Kaura, "A novel control to actively damp resonance in input LC filter of a three-phase voltage source converter," IEEE Trans. Ind. Appl., vol. 33, no. 2, pp. 542-550, Mar./Apr. 1997.

[26] F. F. M. El-Sousy, F. M. H. Khater, and F. I. Ahmed, "Design of one-degree and two-degrees of freedom controllers for indirect field orientation control induction machine drive system," in Proc. Can. Conf. Electr. Comput. Eng., vol. 1, May 2001, pp. 21-26.

[27] H. Taguchi and M. Araki, "Two-degree-of-freedom PID controllersTheir functions and optimal tuning," IFAC Proc. Volumes, vol. 33, no. 4 , pp. 91-96, Apr. 2000.

[28] R. Middleton and G. C. Goodwin, Digital Control and Estimation: A Unified Approach. Englewood Cliffs, NJ, USA: Prentice-Hall, 1990.

[29] K. J. Åström and T. Hägglund, PID Controllers: Theory, Design, and Tuning. Research Triangle Park, NC, USA: International Society for Measurement and Control, 1995.

[30] A. Diab, M. Rashed, J. Li, C. Gerada, and S. Bozhko, "Performance analysis of PMSM for high-speed starter-generator system," in Proc. IEEE Int. Conf. Electr. Syst. Aircr, Railway, Ship Propuls. Road Vehicles Int. Transp. Electrific. Conf. (ESARS-ITEC), Nov. 2018, pp. 1-7.

[31] S. Li, B. Sarlioglu, S. Jurkovic, N. R. Patel, and P. Savagian, "Analysis of temperature effects on performance of interior permanent magnet machines for high variable temperature applications," IEEE Trans. Ind. Appl., vol. 53, no. 5, pp. 4923-4933, Sep. 2017.

[32] S. Walz, R. Lazar, G. Buticchi, and M. Liserre, "Dahlin-based fast and robust current control of a PMSM in case of low carrier ratio," IEEE Access, vol. 7, pp. 102199-102208, 2019.

[33] Á. Tihamér, S. Dadvandipour, and J. Futás, "Influence of discretization method on the digital control system performance," Acta Montanistica Slovaca, vol. 8, pp. 197-200, Dec. 2003.

[34] H. Kim, M. W. Degner, J. M. Guerrero, F. Briz, and R. D. Lorenz, "Discrete-time current regulator design for AC machine drives," IEEE Trans. Ind. Appl., vol. 46, no. 4, pp. 1425-1435, Jul. 2010.

[35] R. C. Dorf and R. H. Bishop, Modern Control Systems. Upper Saddle River, NJ, USA: Prentice-Hall, 2000.

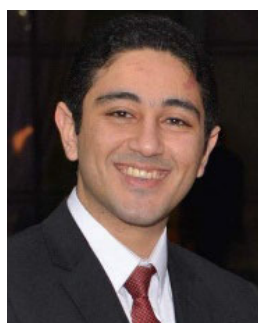

AHMED M. DIAB (Graduate Student Member, IEEE) received the B.Sc. (Hons.) and M.Sc. degrees from Zagazig University, Zagazig, Egypt, in 2011 and 2016, respectively. He is currently pursuing the Ph.D. degree with the University of Nottingham Ningbo China and the Institute for Aerospace Technology (IAT), University of Nottingham, Nottingham, U.K. From 2011 to 2016 , he was a Researcher and a Teaching Assistant with the Department of Electrical Power and Machines, Zagazig University. His research interests include modeling, control, and stability in high-speed motor/generator systems for transportation electrification applications and in variable-speed wind generators.

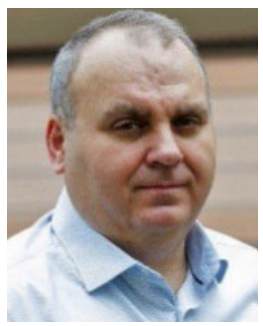

SERHIY BOZHKO (Senior Member, IEEE) received the M.Sc. and Ph.D. degrees in electromechanical systems from the National Technical University of Ukraine, Kyiv, Ukraine, in 1987 and 1994, respectively. Since 2000, he has been with the Power Electronics, Machines and Controls Research Group, University of Nottingham, Nottingham, U.K., where he is currently a Professor of Aircraft Electric Power Systems. He is leading several EU- and industry-funded projects in the area of electric power systems for aerospace, including power generation, distribution, and conversion, power quality, control and stability issues, power management and optimization, advanced modeling, and simulations methods.

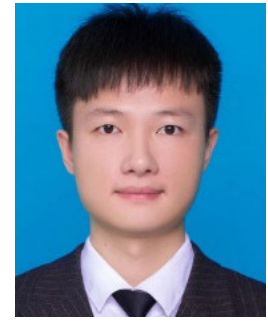

FENG GUO (Student Member, IEEE) received the B.Eng. degree from the China University of Mining and Technology, Xuzhou, China, in 2014, and the M.S. (Hons.) degree from Northeastern University, Shenyang, China, in 2017, both in electrical engineering. He is currently pursuing the Ph.D degree with the Power Electronics, Machines and Control Group, University of Nottingham, Nottingham, U.K.

From 2016 to 2017, he was a visiting student with The Chinese University of Hong Kong, Shenzhen, China. His research interests include pulse-width-modulation strategy, multilevel converters, diagnosis and fault tolerance control of power converters, high-speed motor drives, and the more-electric-aircraft technologies. He was awarded as the Outstanding Graduate Student in 2017.

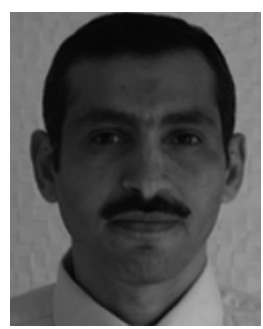

MOHAMED RASHED (Member, IEEE) received the $\mathrm{Ph} . \mathrm{D}$. degree in electrical motor drives from the University of Aberdeen, Aberdeen, U.K., in 2002. He was a Postdoctoral Research Fellow with the Department of Engineering, University of Aberdeen, from 2002 to 2005 and from 2007 to 2009. In 2005, he became an Assistant Professor with the Department of Electrical Engineering, Mansoura University, Mansoura, Egypt, and then on leave from 2007. In 2008, he became an Associate Professor with Mansoura University. In 2009, he joined the Power Electronics, Machines and Control Research Group, Department of Electrical and Electronic Engineering, University of Nottingham, Nottingham, U.K., where he is currently a Senior Research Fellow. His current research interests include the design and control of electrical motor drives and power systems for aerospace applications, power electronics for microgrids, renewable energy sources, and energy storage systems.

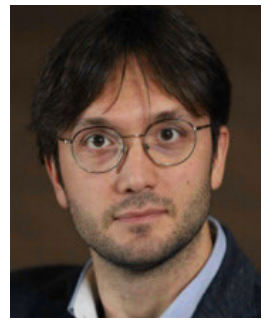

GIAMPAOLO BUTICCHI (Senior Member, IEEE) received the master's degree in electronic engineering and the Ph.D. degree in information technologies from the University of Parma, Parma, Italy, in 2009 and 2013, respectively. In 2012, he was a Visiting Researcher with the University of Nottingham, Nottingham, U.K. From 2014 to 2017, he was a Postdoctoral Researcher and a Guest Professor with the University of Kiel, Germany. In 2017, he was appointed as an Associate Professor of Electrical Engineering with the University of Nottingham Ningbo China and the Head of Power Electronics with the Nottingham Electrification Center. He was promoted to a Professor, in 2020. He is the author/coauthor of more than 210 scientific articles. His research interests include power electronics for renewable energy systems, smart transformer fed microgrids, and dc grids for the more electric aircraft. He is one of the advocates for de distribution systems and multiport power electronics onboard the future aircraft. He was a recipient of the Von Humboldt Postdoctoral Fellowship to carry out research related to fault tolerant topologies of smart transformers, during his stay in Germany. He is an Associate Editor of the IEEE Transactions on Industrial Electronics, the IEEE Transactions on Transportation Electrification, and the IEEE Open Journal of the Industrial Electronics Society. He is currently the Chair of the IEEE Industrial Electronics Society Technical Committee on Renewable Energy Systems. 


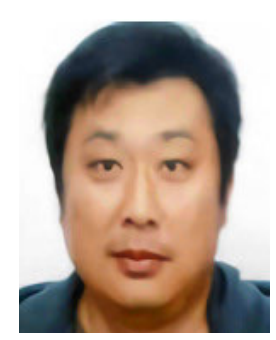

ZHUANG XU (Member, IEEE) received the M.Eng.Sci. and Ph.D. degrees in electrical engineering from the University of New South Wales, Sydney, NSW, Australia, in 1999 and 2006, respectively. From 2001 to 2005, he was with the Energy System Group, University of New South Wales. In 2006, he was an Associate Professor with the Harbin Institute of Technology, Harbin, China. $\mathrm{He}$ is currently an Associate Professor with the Electrical and Electronic Engineering Department, University of Nottingham Ningbo China, Ningbo, China. He is a member of the Power and Energy Society, in 2017. His research interests include power electronics and high-performance electrical drives. He was a recipient of three best paper awards from the Annual Conference on the IEEE Industrial Electronics Society, in 2004, the IEEE International Conference on Electrical Machines and Systems, in 2010, and the IEEE International Conference on Power Electronics and ECCE Asia, in 2011.

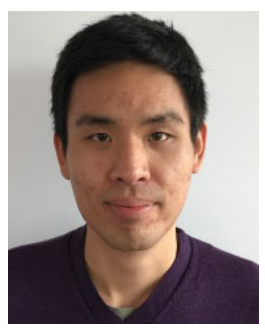

SEANG SHEN YEOH received the M.Sc. degree in power electronics and drives and the Ph.D degree in electrical engineering from the University of Nottingham, Nottingham, U.K., in 2011 and 2016, respectively.

Since 2016, he has been a Research Fellow with the Power Electronics, Machines, and Control (PEMC) Research Group, University of Nottingham. His current research interests include modeling and stability studies of complex power systems, and control strategies for power electronic drive systems.

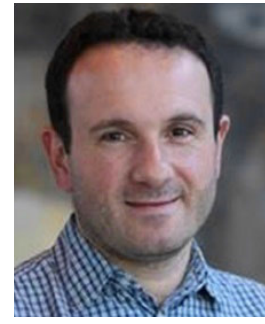

CHRIS GERADA (Senior Member, IEEE) received the $\mathrm{Ph} . \mathrm{D}$. degree in numerical modeling of electrical machines from the University of Nottingham, Nottingham, U.K., in 2005. He subsequently worked as a Researcher with the University of Nottingham on high performance electrical drives and on the design and modeling of electromagnetic actuators for aerospace applications. In 2008, he was appointed as a Lecturer in electrical machines and an Associate Professor, in 2011. In 2013, he was appointed as a Professor with the University of Nottingham. His main research interest includes the design and modeling of high-performance electric drives and machines. He was awarded as a Research Chair from the Royal Academy of Engineering, in 2013. He serves as an Associate Editor for the IEEE Transactions on Industry ApPLICATIONS. $\mathrm{He}$ is the past Chair of the IEEE IES Electrical Machines Committee.

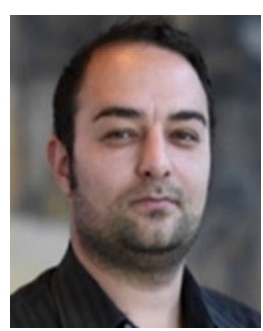

MICHAEL GALEA (Senior Member, IEEE) received the $\mathrm{Ph} . \mathrm{D}$. degree in electrical machines design from the University of Nottingham, Nottingham, U.K., in 2013. He was appointed as a Lecturer, in 2014, as an Associate Professor, in 2018, and as a Professor of Electrical Machines and Drives, in 2019, with the University of Nottingham. He is currently the Head of the School of Aerospace, University of Nottingham Ningbo China, where he is also the Director of Aerospace. He currently lectures in Electrical Machines and Drives and in Aerospace Systems Integration and manages a number of diverse projects and programs related to the more/all electric aircraft, electrified propulsion, and associated fields. His main research interests include design and development of electrical machines and drives (classical and unconventional), reliability and lifetime degradation of electrical machines, and the more electric aircraft. $\mathrm{He}$ is a fellow of the Royal Aeronautical Society. He is on the Executive Board of the U.K. Magnetics Society. 